\title{
Cultivating Attainment through Imagination in Religious Education Classes
}

\author{
Mahir S. Al-Hawamleh \\ Al al-Bayt University \\ Al-Mafraq, Jordan
}

\begin{abstract}
Previous studies (e.g. Whitton 2018; Damiani, \& Paloma, 2017; Egan, 2005) on imagination asserted its role to facilitate the development of members' spirituality and thereby attainment. In the present study, the promotion of imagination is explored. Altogether, 58 fifteen year old male students were trained to think imaginatively through considering their psychological factors of: attention, abilities, outcomes, motivation, and ongoing assessment. Varied accounts of the class settings encompassed recorded videos of students' imaginative processes during class, teacher's debates, students' stimulated recall, observations and photos of the classroom. After the training, the study demonstrated a significant noteworthy improvement in favor of the imaginative approach.This research has offered evidence to describe imaginative practices as effective in developing students' attainment.
\end{abstract}

Keywords: Imaginative approach; religious education; 15 year old males; case study, Jordan.

\section{Introduction}

The process of teaching and learning is dynamic as the advent of new horizons has caused further complications in the development of teaching. Educators are currently criticized if they can't tailor best opportunities to enhance their students' performance. Of course, the role of education is to re-theorize as constructing human assets by providing students with innovative and imaginative capabilities on top of knowledge delivering (NACCCE, 1999; Wilson, 2005; Griffiths, 2014)).

Obviously, the need for 'thinking skills' education has mostly focused on the development of teaching and learning principles which encourages inquisitiveness, creativity, imagination, self-knowledge, and powers of intelligent analysis and reflection. Imaginative thinking has the potential effect of enhancing students' religious knowledge. Key aims of education are as follows: creating learning experience as relevant, applicable and significant to students, and thereby interesting. A major effect of imaginative teaching for students was an instant involvement in the active, responsive, appealing, and 
caring attitudes (Jeffrey \& Woods, 2003). In different sections of this study, the author reviews the types of interrelated research information about imaginative teaching that may guide educators on how best to augment their students' performance.

To deal with this mind boggling teaching act (viz. attainment), educators all over the world must get to be comfortable with the kind of data that helps learners think, reason and to respond to questions, problems and challenges. Here, the use of imaginative teaching in education has recognized beneficial in many regards. Not only has it been established to facilitate student learning (Egan, 2005) but it has also been reported to enhance learner's skill to absorb novel instruction autonomously, process information analytically, reason critically, and work out difficulties (Lin, 2010).

Education reform acts such as curriculum reforms sated by National Advisory Committee on Creative and Cultural Education (NACCCE) have been established in education policy in western countries for example the USA and Europe (Craft, 2007; Shaheen, 2010). Lake Research Partners, for example, conducted a poll on the USA entitled as 'The Imagine Nation 2008' reported that nearly 9 in 10 participants indicated that imagination augments and expands their creativity and accomplishment in economy. Educational reform, therefore, is necessary to develop learners' potentials (Jun, Wu \& Al-banese, 2010).

Formerly, Steiner (1997) set forth the notion of all-inclusive and imaginative education through typical imaginative teaching ways and means (specifically arts, exploration, discussion and empathy, routine, drama, storytelling) over phenomenological events, trailed by debating and scaffolding. Steiner (1997) reported that imagination is essential to a student's general development. He supposed that imaginative education not only improve student's individual life but directs him or her in the direction of meaning in the world. Steiner believed that children between seven and 14 are the most receptive to creative stimuli (i.e. early childhood, primary, secondary).

This study explores the notions and conduct of imaginative instruction which received worldwide consideration (e.g. Egan, 2005). In the imaginative approach, the students and teacher involve in a more imaginative approach to the instructional process. The student's imagination can be a chief component of the process of exploring information (Woods \& Jeffrey, 1996). The present research, however, is a welcome development teaching and learning approach which brings around spirituality in religious education classes which stimulated among its supporters a spirit of intellectual curiosity and creativity, eventually causing in that superb era of learning and scientific research which famed educational innovations.

Investigations of imaginative thinking (Harris; 2000) provided proper and sound grounds for finding out sociocultural ideas of imaginative scaffolding. For example, Eisner (2002) established that considering it as a mental effort is 
essential for enabling teachers to stimulate innovative thoughts regarding religious education learning.

Vygotsky as cited in Gajdamaschko (2005) described the relationship between the internalization processes and the imaginative processes in children as very interrelated and indicative of their imaginative and innovative abilities. Vygotsky identified the constituents of an educational setting that can either upkeep or suppress student's imaginative capacities. Vygotsky identified two kinds of reasoning performances. Of special focus, performances that just demonstrate earlier practices and they do not have a creative excellence, followed by practices that he called imaginative practices. This imaginative performance is based on the brain's ability to elicit features from past experiences. Of course, any imaginative action is the core for all open-minded intellectual efforts.

Urbach (2006) studied oral storytelling performance in an urban $1^{\text {st }}$ grade setting over a period of four months. The participants in Urbach's storytelling group comprised adult and learner storytellers equally. Although Urbach's study did not pursue to discover students' creative conduct, the analysis of the research data showed the prevailing role of imagination in students' thinking through students' ability to comprehended oral stories as one way towards literacy.

Lin (2010) presented an outline of creative pedagogy and attempted to inspire educationalists to re-consider perspectives, methods and strategies that foster creativity. Lin taught a number of drama lessons was intended and introduced to appreciate imaginative practices by Taiwanese teachers along with their students. The result demonstrated that the students thought that the lessons were effective in improving some creative talents, for example imagination, autonomous thinking, and risk-taking. Effective strategies included: creativity, liveliness, task-based learning, and cooperative learning. Here, teacher's guidance was reported, by the participants, as employed mostly in drama lessons.

Environmental and psychological variables proved to affect surely students' imaginative ability development. Liang, Chaoyun, Hsu, Yuling \& Chang, ChiCheng (2013) examined the role of each of intrinsic motivation,_inspiration through action, self-efficacy_and negative emotion on the imaginative ability. The sample of the study consisted video/film major university students. Liang et al highlighted the crucial role of intrinsic motivate. Here, intrinsic motivation acted as a facilitating the growth of learner's imaginative competence. The study further reported that both inspiration through action and self-efficacy verified helpful, constructive and direct impact on generating imagination, though negative emotion verified an undesirable impact on imagination.

Emjawer and Al-Jamal (2016) investigated the effect of imaginative strategy on Jordanian $10^{\text {th }}$ grade students' grammar performance. Two intact section (30 students each) took part in the study and were assigned randomly one as experimental and one as control. To achieve the aim of the study, the 
instructional material was redesigned to fit with imaginative activities. Then two instruments were developed; specifically a test and an observation checklist. The results of the study indicated that the imaginative-instruction based group outperformed their counterparts in the control group as statistically significant differences were pinpointed in favor for the experimental group. Using imagination for grammar instruction maximized students' awareness to grammar awareness as a result of using the grammar rules markedly.

Deserting the philosophy and practice of holistic education in Jordan, has steered schools (as associated with testing) towards utilitarian objectives. The provision of a 'workforce' to initiate national economic performance as a top priority in education will have undesirable effect on the morale of students. Disaffection and truancy are prevalent and even despair are increasing disturbingly in the midst of young people. Accordingly, the present study aims at increasing students' awareness of the moral and spiritual dimension which provokes an authentic vision of human excellence, through improving logical reasoning and analysis via imaginative approach that involves the deeper needs of the human spirit.

For improving the quality of teacher-learning relationships, Damiani and Paloma (2017) trained 45 Italian teachers as allocated into three groups on imaginative skills. The groups were selected from three distinct secondary schools. To achieve the aim of the study, teachers were trained for one whole year which followed 5 phases consistent to 5 seminars on imaginative practices. These are: the verbal stage, followed by cases with problems. After that, students' traits were analyzed and considered. Then narratives that make teachers as heroes were composed. Here, the narrative method of the imaginative approach enabled the happening of observable developments in teachers' practices which was firstly perceived in stories and at that moment lived and observed. The study reported the effectiveness of the imaginative technique as an intermediate device that enabled teachers to discover different features relevant to their testing, emotional, and cultural skills along with their positive attitudes.

Whitton (2018) investigated ways of cultivating imagination, the source of ideas as she describes it, among university tutors. To achieve the aim of the study, Whitton described two disciplines that are based on imagination. One discipline was physics which is a non-art discipline, and the other was history which is an art discipline. Whitton found out overflowing confirmations that student's imagination can be the cultivated and intensely infused in the methods, techniques, procedures, designs of any discipline as it enables students to contemplate and perform similar to a historian, physicist, etc.

Imagination worked very well with twelve blind and thirteen deaf culturally varied students. To this end, Smith (2018) investigated the effect of introducing an imaginary friend connected with each student as such groups of students have problems with making social and emotional relations with others and thereby mostly alone. The study reported that more than half of the participants 
(viz. 54\%, mostly from the deaf group) imagined playing with such imaginary friend and consequently had better societal and emotional participation.

In a collaborative effort by a group of researchers at the Open University in Norway (Ferguson et al. 2019) reported ten teaching pedagogies inspire students to be creative and innovative and thereby will have a profound impact on education. One key recommended technique that accompanied most pedagogies of teaching was imagination. Imagination was reported as key in five pedagogies; namely: playful learning, learning with robots, decolonizing learning, learning through wonder.

All in all, this study opted to suggest a change from long recognized approaches and methods, towards teaching of religious education through examining the impact of the imaginative approach in religious education classes. The purpose of this study, specifically, was to shape and develop students' achievement on religious education classes. Thus, the study claimed the following question:

What is the effect, if any, of the imaginative approach upon the attainment of tenth grade students at religious education classes as reflected in their achievement test scores, classroom observations, video recording, stimulated recall, and the interview with the teacher?

\section{Method}

Case study was selected as the research design of the current study. This research type has been referred to by many authors as a research tactic. For example, Yin (2003:13) identified it as "an empirical inquiry that investigates a contemporary phenomenon within its real life context". Of course, it encompasses the gathering of wide-ranging data from numerous bases that offer a detailed account of the problem being examined. This research strategy is typically confined with regard to the span of time spent in the study context along with the situations in which data are elicited and gathered. It is very likely in such research comprise learners' details together with teacher's conduct.

a) The teacher: The settings of this study involved a religious education teacher who has been selected purposefully because of his awareness of the practices of constructivism as he is one of researcher's enthusiastic students. This teacher has been given pseudonym as ' $\mathrm{A}$ ' teacher. ' $\mathrm{A}$ ' teacher has a relatively long teaching experience as that of ten years. He is currently teaching the tenth grade and regarded as proficient by colleagues in his schools. 'A' teacher considered the imaginative approach as significant where he encouraged students to exchange thoughts, as sustained by positive feedback and opportunities and freedom for their spontaneity. He also thought that a stress-free atmosphere is crucial for students to grow their imaginative thinking and consequently develop their achievement as well as their self-esteem in religious education classes.

b) Fifteen year old male students: The other key participants were tenth grade students in ' $\mathrm{A}$ ' teacher case study school. The total number of participants was that of 58 as randomly assigned onto two (experimental and control) groups with pretest $\backslash$ posttest design. The equivalency of the 
two sections was checked by means of a general religious education test at the beginning of the first semester of 2018/2019 academic year.

\section{Procedures}

In the current study, cultivating attainment was aimed. First, a convenient sample of one basic school in Irbid, Jordan was chosen, and two classes at were randomly assigned. Here, the teacher is one of the researcher's most enthusiastic student's towards novel trends in education. Second, the pre-test was administered to see the homogeneity of the participating students. Next, treatment took place.

Teaching imagination for $10^{\text {th }}$ graders fitted the most procedures provided by Egan's (2005) account in that imaginative approaches make learning stimulating and real. The structure of this type of learning has many objectives. A major influence to school's major aims; which were to enhance students' achievement and make the learning process relevant and interesting.

Religious education class was made exciting for learners participated in the study who practiced in a wide range activities revealing an entire range of pleasures and passionate experiences, religious knowledge was established and enhanced as a passion for investigation, innovation and research; thereby delivering a powerfully attentive tasks encompassing problem solving strategies.

Confirming the applicability of the teaching to $10^{\text {th }}$ graders steered to possession of cognitive outcomes, procedural knowledge outcomes that end up in attaining the targeted skills and competencies. Here, this can be achieved as learners are engaged in an open learning process associated with their interests (Pollard \& Filer, 1996). Agreeing with Winnicott (1964), learners can attain their goal easily if they feel that they embrace their setting as well as the individuals in it. Equally, learners turn into more communally active as they increasingly develop consciousness which reflects their control of the setting past themselves. The voluntary teacher explained students' ownership of the curriculum. Specifically, the teaching learning situations that frame imaginative the participating students' involvement is presented next.

\section{The Imaginative Approach}

The learning experiences offered to tenth grade students during the class entailed the following teaching procedures the imagination teaching principles (Egan, 2005). The characteristics of effective imaginative teaching are

- Calling all students' attention, encouraging them to believe in their imaginative identity, fostering imagination by fostering abilities and thoughtfulness of imagination towards photographs of key themes to be discussed, hands on approach.

- Identifying students' imaginative abilities by letting students participate in the narrative process. Of course, individuals like listening to stories, 
but at the same time they opt to rebuild them. The voluntary teacher tells stories from the prophetic tradition.

- Enabling students to ascertain the necessary, required and needed learning objectives on their own. Here, learners experience the learning process per se in order to be capable of solving the problems allied to the lesson.

- Motivating students, as per Egan (2005:6) establishes, "All the subjects of the curriculum have mysteries attached to them, and part of our job in making curriculum content known to students is to give them an image of richer and deeper understanding that is there to draw their minds into the adventure of learning".

- Creating appealed sense of mystery and intrigue. Bright students will be restless and eager to solve this problem on their own

- Using metaphors in instruction. Here, metaphor is a fruitful gadget that most teachers like to employ at their disposal of any subject. To this end, Egan (2005) alternatively highlights metaphor as essential and crucial metaphor as cognitive gadget for enhancing student's learning.

- For evaluating the students; the voluntary teacher asks students to write down the routine which, in turn, allows them categorize problems and set the practice in their own way. Specifically, it helps students' grasp of the instructional point; thereby effective attainment of outcomes takes place.

\section{Instrument}

(i) Achievement test: a 30 multiple-choice item achievement test was developed so as to assess students achievement in religious education. One example is: Imagine that you are thinking about going to Aqaba on a holiday; reflect your ethics of collaboration in cleaning the shore by:
a) volunteering if invited
b) not throwing any litter
c) inspiring other to act by telling
d) inspiring others to act by demonstrating

Here, the pre-test was applied to ascertain equivalence between the two groups, the experimental and the control, concerning attainment before the start of the training. The same test was applied after the training to catch on any marked differences between the findings of the control group (28 students) and the experimental group (30 students) owed to the effect of the imaginative approach to the experimental group and the conventional method to the control groups.

The participants on both groups (viz. the experimental \& the control) were informed about the test as to be used with the intention of research rather for personal reasons. They were invited to answer correctly and fairly. Participating students were allocated in two intact sections; the exam lasted for thirty minutes. Upon the completion of the training, the post- test was managed by means of the same ways. 
The researcher submitted the achievement test, interview sheet, stimulated recall sheet, observation checklist to a jury of educational experts to moderate the instruments' language suitability, truthfulness and for its matching for students' levels. The recommendations delivered by the jury were taken into respect and considered in the final version of the research tools.

Reliability measures of the achievement test were realized through giving it to $1510^{\text {th }}$ grade students who were later excluded from the sample. The test was given to the same respondents after two weeks. Pearson reliability co-efficient was calculated as 0.89 . This score was considered appropriate for implementing the tools of the present study. Then, a t-test was employed to highlight noteworthy differences in students' attainment between the two groups as resulted from the teaching method use (viz. imaginative, conventional).

The case study was place over a two-month duration (eight weeks) in first semester of the academic year 2018-2019 where the researcher visited the school at least three times a week for 8 weeks. The timing of the regular visits was carefully thought out in light of religious education class timetable. The reason behind such long period was the need to make students acquainted with one another, so that their interaction and exchange of activities. That is data were collected by the means of: observations, recorded videos, stimulated recall with teachers and informal interviews with the teacher. Each is presented sequentially. Each is presented sequentially.

(ii) Observation: Regular observations of the religious education teacher (pseudo symbol: A) was conducted according to a schedule of observations in light of his timetable. As the school was located in Irbid city area, approaching it was convenient to the researcher who lives in the same area. Accordingly, there were 24 observations for the classes of each religious education teacher.

Observations of teacher ' $\mathrm{A}$ ' and tenth grade students were carried out simultaneously, and field transcripts were recorded during observation. During the observations, the researcher recorded whatever he "heard, saw, experienced and thought in the course of collecting on the data" Bogdan, \& Sari Knopp Biklen, 2003: 111). At the end of every period, the researcher reflected on his field notes and modified these instantly once each observation period ended. These transcripts enclosed "thoughts, feelings and ideas which provided further focus for the next phase of data collection and analysis" (Bogdan, \& Sari Knopp Biklen, 2003: 151). Each observation was printed on a PC as recommended by Bogdan and Sari Knopp Biklen, (2003: 110):

"I recorded descriptions of the people, objects, places, events, activities, and conversations; in addition, I kept records of "ideas, strategies, reflections and hunches" and noted patterns as they emerge"

In order to be aware with the school context, the researcher spent a week before starting the observation period as experiencing the culture of school and to 
establish rapport with the tenth grade students and religious education teacher. Each video-taped observation lasted for 45 minutes.

The observation of students established what Cohen, Manion \& Morrison (2007: 120) perceived to be a case study procedure of examining "the phenomena that compose the daily life and events of that unit, in order to advance generalizations about the wider community of which the unit is a part. These observations focused on both teacher A's communications, strategies and level of scaffolding of students' imaginative behavior during class.

(iii) Video Recording: In the current study, video recording was employed in order to capture the teacher-student and student-student interactions during. The videos provided a wide-ranging observation of the classroom, in addition to a closer attention on individual students when engaged in imaginative thinking activities. Video offers a technology not merely reachable to understand observations more, but it also adds the value of recurrent watching. Of course, this is valued in data transcription and analysis (Silverman, 2000). The videos, in the present study, were analyzed from examples of scaffolding while reporting the same themes of the observation; that is, teacher participation, involvement, attitudes toward students' imaginative thinking, openness to interactions, strategies and approaches to guide imaginative thinking.

(iv) Stimulated recall sheet: it is considered as a subclass of research methods which acknowledges teachers' mental images (Mackey \& Gass, 2005). In the current study, students may possibly want "visual evidence to remind them of a situation or just to stimulate their ideas" (Gray, 2004, p. 385). Plaut (2006) and Sime (2006) proposed that stimulated recall should take place once the task is finished. Thus, the researcher carried out the stimulated recall of students three weeks after the accomplishment of the eight week training period. The researcher met the students alone in school's meeting room that has a T.V set, which was agreed prior to telephone call.

(v) Interview sheet with ' $A$ ' teacher: Once the observations for 8 weeks have taken place, the researcher asked teacher ' $\mathrm{A}$ ' for an interview in his school. This interview happened on December, one month after the observations were concluded. The interview method is a conversation with a purpose where the researcher elicited info on the knowledge, values, preferences and attitudes of the participant (Cohen, Manion \& Morrison, 2007). The researcher employed open- ended interview techniques to get more info about the teacher ' $A$ ' viewpoints regarding scaffolding students' extended imaginative thinking in the classroom.

\section{Data analysis}

Case Study: the researcher used an observation form as a guide to event analysis. On the other hand, the researcher transcribed the videotapes of classes. After that, all transcripts were typed as implied by Rose (2012). Comments in relation to field notes were written in way that can be tracked easily. Salient aspects of the data included teachers' scaffolding strategies, and practices. All such comments were edited to form themes with key aspects of the imaginative 
events observed. The themes offered an in-depth account that established a sequential flow of events (Rose, 2012).

Based on coding on a scale categories as developed by the researcher, tenth grade students' imaginative engagement was ranked on a five-point scale (i.e., very limited, limited chances to acquire knowledge by the means of discovery learning, wide range of chances for innovation, openness with countless chances for personality and discovery-learning, and unlimited chances for imaginative thinking). Interview: The researcher recorded the interview with teacher ' $\mathrm{A}$ '. Then the researcher extracted teacher's responses that were directly related to research questions then placed the confirmation of themes stated by the current study. Stimulated recall: In this study, it was used to elicit students' performance during scaffolding ideas in class.

\section{Findings}

The research question reads as: What is the effect, if any, of the imaginative approach upon the attainment of tenth grade students at religious education classes as reflected in their achievement test scores, classroom observations, video recording, stimulated recall, and the interview with the teacher? Both groups (viz. the experimental \& control) sat for the pretest which was then corrected, marked and statistically analyzed. Specifically, the following Table displays the results.

Table 1. T-test of experimental and control groups on the pre-test

\begin{tabular}{cccccc}
\hline Group & $\begin{array}{c}\text { Number of } \\
\text { students }\end{array}$ & $\begin{array}{c}\text { Mean } \\
\text { scores }\end{array}$ & $\begin{array}{c}\text { Standard } \\
\text { Deviation }\end{array}$ & t-value & $\mathbf{P}$ \\
\hline Experimental & 30 & 8.266 & 2.71 & 0.647 & 0.521 \\
Control & 28 & 7.857 & 2.03 & & \\
\hline
\end{tabular}

Table 1 clarifies no differences in the mean scores and the standard deviations measures of the experimental group which reads as 8.266 and 2.71 respectively; with the mean scores and the standard deviation measures of the control group which reads as 7.857 and 2.03 respectively. The results in Table 1 indicate that the scores of the participants in both experimental and control groups are equivalent in terms of their results on the pre-test.

Table 2. T-test of experimental and control groups on the post-test

\begin{tabular}{cccccc}
\hline Group & $\begin{array}{c}\text { Number of } \\
\text { students }\end{array}$ & $\begin{array}{c}\text { Mean } \\
\text { scores }\end{array}$ & $\begin{array}{c}\text { Standard } \\
\text { Deviation }\end{array}$ & t-value & $\mathbf{P}$ \\
\hline Experimental & 30 & 17.600 & 2.25 & 6.912 & 0.000 \\
Control & 28 & 12.428 & 3.37 & \\
\hline
\end{tabular}

The findings in Table 2 designate that there are noteworthy statistical dissimilarities between the mean scores of the two groups under the study that is attributed to the effect of the teaching method. This difference in the mean scores of the experimental group is attributed to the use of the imaginative approach in teaching religious education. Since the participants in both groups tended to be of identical circumstances, no other factors besides the method variable had any effect on the results of the study. The substantial difference 
between the two groups was in favor of the experimental group which used the imaginative approach.

\section{Interview results}

The results summarize religious education teacher's definitions of imagination in general and of the process of imaginative teaching processes in particular. His views on how students' religious education can be fostered through proper settings and scaffolding. The religious education teacher in question seemed to be aware of an overall understanding of imaginative teaching process on top of its benefits in raising students' self-esteem. The participant teacher referred to imaginative thinking as an achievement and a triumph of one's judgments, thoughts and opinions. Imaginative, was further explained by the teacher (viz. A) as a process of thinking. The case study teacher made a connection between imagination and creativity.

\section{Observation results}

Regarding activity types, the observed teacher used role play 15 times, explorations 13 times, drama 14 times; whereas storytelling, discussion and empathy were observed ten times only. Further, students' autonomy was noticed as they were able to respond to open ended questions or imagination based comments more often than students at the control group. Now, these positive results probably stemmed out of the sensitivity of the teacher towards scaffolding students' imagination. The observations pinpointed how the teacher ' $\mathrm{A}$ ' performed as mediator to help students become more creative. Specifically, the observations were centered on how much time and in what ways religious education ' $\mathrm{A}$ ' teacher was concerned in students' interactions and religious education experience. Such observations reported: teacher participation, involvement, attitudes toward students' imaginative thinking, openness to interactions, strategies and approaches to guide imaginative thinking.

\section{Stimulated recall:}

Stimulated recall is a visual record transported student's details for reflection (Rose, 2012). Specifically, talking about the stimulated classes with students participating in this study helped the researcher to describe and draw conclusions about students' imagination progress enhancement and development and thereby self-confidence. The author watched and recoded students' interaction on video recordings. Here, the participants' ability to scaffold, reflect, interpret, justify and explain was crystal clear. In more detail, their scaffolding practices may possibly have improved as a result of imaginative thinking.

\section{Discussion}

The fundamental point in this study cleared up was the effect of cultivating attainment of $10^{\text {th }}$ grade students by the means of the imaginative approach. As it was said, there was no noteworthy difference aimed the groups on the pretest scores, though there were noteworthy and urgent contrasts between them on the posttest. In any case it merits saying that the striking contrasts existed in 
experimental group and the control one. Hence, the distinctions might be credited to the utilization of the imaginative approach for the experimental group of the research.

The results of the current study are in congruence with the results of numerous studies (e.g. Whitton 2018; Damiani \& Paloma, 2017; Emjawer \& Al-Jamal, 2016; Egan, 2005) concerning the valuable use of the imaginative approach in different settings and contexts. Egan (2005) explored the impact of the imaginative approach on cultivating K-12 students' knowledge and creativity. The imaginative tools were those of: agency, story, conflict, play, regularity and meta-narrative thoughtfulness. That significance tend to shape the way learners appreciate their own learning experiences. Interestingly, Mayesky's (2006) perception of students' vision encompassing imagination and thereby ascertaining concepts, ideas, themes relevant to possible solutions skillfully. The case study teacher described imaginative thinking as an innate idea which involves activities that are interrelated with imagination.

The outcomes uncovered an important and positive relationship between the exactness of imaginative tools and students' learning outcomes attainment. Correspondingly this study is congruent with the one conducted by Emjawer and Al-Jamal (2016) who reported the effectiveness of the imaginative approach.

When asked to describe imaginative teaching process during the interviews, the case study teacher stated that these processes are similar to daily life experiences to create as leading to the production of unique ideas and explanations. Inquiring about the features of imaginative students revealed an indication of creative persons are those who have innovative ideas and solution. To the case study teacher, imaginative instruction enabled students to express and interpret feelings and thoughts using diverse way without shyness and limitation. Based on the interview, the participant teacher identified creativity as being constructed on using skills and information, associated with imagination; to this end, novel thoughts can be created. These results are congruent with Egan (2005) who asserted that imagination is essential to a learner's play as it takes the learner from own reality to an involvement of massive alternative cosmoses.

Throughout the observations and on the off chance that this approach is supposed to be correct, it seems that the present study was adequately operational in controlling any mediating variable. It should be specified that during this investigation, the participants appreciated that no high-stake chance was to be made to their way of thinking. Nevertheless the point that, the participants established no assurance and willingness in the first place, they were always motivated to understand that they can make it. Further, it must be acknowledged that the participants were given a response sheet entailing full portrayals, plans, and scripts on what highlights best images.

Luckily, the current study got the chance to observe a skilled teacher, who cotaught elements of lessons with adult roles involvements in an approach that is imaginative and elastic. Here, play aroused students imagination and expanded 
their understanding of the world they live in. More specifically, in every observed class, the trained teacher was concerned with how to shape the content of each single lesson about the religious education in a way that provokes students' emotive significance. Thus, a scaffolding of the endings of any targeted story or even the aspects of a given topic.

In the current research, it was also found that the experimental group presented modifications in their ordinary rating of spirituality after eight weeks training sessions on imagination. Here, the differences between the two bunches (viz. control \& experimental) are in the extent they had developed in scoring as remarkable. In other words, the effects of the imaginative approach on the rating precision of the two groups were dissimilar, in favor of the experimental group. Accordingly, the decision is that the more able students get in their attainment, the more spiritual they will get, and regularly the more thoughtful and creative.

\section{Conclusion}

This study explored the effects of the imaginative approach on cultivating attainment on religious education classes in Jordan. The results gained by this research lend themselves to certain pedagogical implications. These implications are of great help for teachers as well as learners. Diverse stakeholders in the field of religious education learning and teaching course and syllabus writers, learners, teacher trainers can also gain positive advantages of the attained outcomes. Using the findings of this study can recover, amend and enhance the state and status of religious education instruction manner in any context; and not only in Jordan, but rather worldwide. The conclusions may encourage teachers, who still believe in their own conventional techniques in teaching religious education to change their practices and follow more innovative approaches.

This study of highlighted the role of imagination and how it is used in religious education classes. At its core is a centralization of achievement, thoughts and feelings. The findings are similar to Egan's ( 2005) and Steiner's (1997) who are the founders of this approach, Harris's in sociology, Eisne'sr (2002) and Damiani and Paloma's ( 2017) in teacher's role in cultivating imagination, Emjawer and Al-Jamal's (2016) EFL grammar, Whitton's (2018) art and non-art based disciplines. Imaginative instruction is more than an approach or a technique, it's rather a performance shaper. It worked for deaf and blind learners (Smith, 2018).

With regards to the results of the study, imaginative tools have been used in order to enhance students' attainment and spirituality because the use of such tools makes the religious education classes pleasurable, amusing and inspires students. It delivers a stimulating class which attracts students' attention. As a result, it helps to achieve a better attainment scores.

In light of the conclusions of this study, the imaginative approach created spiritual positive changes that were apparent on students' performance. These changes had the potential of making the religious education classes as more 
creative, active, sociable, and collaborative, and therefore students can appreciate the sense of self-confidence. Here, students are creative, autonomous and accountable for their own learning and become more assertive about their thinking skills. Once teachers give students the chance to actively participate in their learning, their spirituality will become more positive as imagination is the central part of this changing process.

\section{References}

Bogdan, R. C., \& Sari Knopp Biklen, S. K. (2003). Qualitative research for education: An introduction to Theories and Methods ( $4^{\text {th }}$ ed.). Boston: Allyn and Bacon.

Chang, Hsiang-Tang, \& Lin, Tung-I (2013). Discovering Taiwanese design college students' learning performance and imaginative capacity, Thinking Skills and Creativity, 10: 23-39.

Craft, A. (2007). Possibility thinking in the early years and primary classroom. In A. G. Tan (Ed.), Creativity: A handbook for teacher (pp. 231-250). Singapore: World Scientific. doi:10.1142/9789812770868_0013

Damiani, P., \& Paloma, F. G. (2017). Imagination as an educational tool for teachers. The development of emotional-relational skills through the "landscape narration" method. Proceeding at International and Interdisciplinary Conference IMMAGINI? Image and Imagination between representation, communication, education and psychology. Brixen, Italy, 27-28 November. Proceedings, 1, 927, 113. doi:10.3390/proceedings1090927.

Egan, K. (2005) .An imaginative approach to teaching [e*book]. Retrieved August 13, 2018, from Amazon: http://www.Amazon.com

Eisner, E. W. (2002). The arts and the creation of mind. New Haven, CT: Yale University Press.

Emjawer, Sumaya and Al-Jamal, Dina (2016) An imaginative approach to teaching grammar . Journal of Educational Sciences. 28(1), 183- 202.

Ferguson, R., Coughlan, T., Egelandsdal, K., Gaved, M., Herodotou, C., Hillaire, G., ... Whitelock, D. (2019). Innovating pedagogy 2019: Open University innovation report 7. Milton Keynes: The Open University. Retrieved from https://iet.open.ac.uk/file/innovating-pedagogy-2019.pdf

Gajdamaschko, N. (2005). Vygotsky on imagination: Why an understanding of the imagination is an important issue for schoolteachers. Teaching Education, 16(1), 13-22.

Gray, D. E. (2004). Doing research in the real world. London: Sage Publications.

Griffiths, Morwenna (2014). Encouraging imagination and creativity in the teaching profession. European Educational Research Journal, 13(1), 117- 129.

doi:10.2304/eerj.2014.13.1.117

Harris, P. L. (2000). The work of the imagination. Malden, MA: Blackwell Publishing. Imagine Nation (2008). New poll reveals stifling imagination in schools underlies innovation and skills deficit. Retrieved May 6, 2008, from http://www.lakeresearch.com/polls/BG082008.htm

Jeffrey, B. \& Woods, P. (2003). The creative school: A framework for success, quality and effectiveness, London: Routledge.

Liang, Chaoyun, Hsu, Yuling \& Chang, Chi-Cheng (2013). Intrinsic motivation as a mediator on imaginative capability development. Thinking Skills and Creativity. 8, 109-119.

Lin, Y-sien (2010). Drama and possibility thinking - Taiwanese pupils' perspectives regarding creative pedagogy in drama. Thinking Skills and Creativity, 5(3), 108119. doi:10.1016/j.tsc.2010.09.001

Mackey, A., \& Gass, S. M. (2005). Second language research: methodology and design. Mahwah New Jersey: Lawrence Erlbaum Associates. 
Mayesky, M., (2006.). Creative activities for young children (8 $\left.8^{\text {th }} \mathrm{ed}.\right)$, Australia: Delmar/Thomson Learning.

NACCCE (1999) All our futures: creativity, culture and education, London, DfEE.

Plaut, S. (2006). "I just don't get it": Teachers' and students' conceptions of confusion and implications for teaching and learning in the high school English classroom. Curriculum Inquiry, 36(4), 391-421.

Pollard, A., \& Filer, A. (1996) The social world of children's learning: case studies of children from four to seven, London: Cassells.

Rose, Gillian (2012). Visual Methodologies: An Introduction to Researching with Visual Materials. Sage publication limited. London: Routledge.

Shaheen, R. (2010). Creativity and education. Creative Education, 1, 166-169. doi:10.4236/ce.2010.13026

Sime, D. (2006). What do learners make of teachers' gestures in the language classroom?. International Review of Applied Linguistics in Language Teaching, 44(2), 211-230.

Smith, Maureen Claire (2018). Imaginary companions of blind, deaf, and typically developing school children. Imagination, Cognition and Personality, 38(3), 290-314. Retrieved from https://doi.org/10.1177/0276236618761371

Steiner, R. (1997). The roots of education. Hudson, NY: Anthroposophic Press.

Urbach, J. (2006). The door into Narnia: Orchestrating a broader view of literacy (Unpublished doctoral dissertation). University of Colorado, Boulder, CO.

Whitton, Joy (2018). Fostering imagination in higher education: Displinary and professional practices. Routledge.

Wilson, A. (Ed.) (2005). Creativity in primary education: Theory and practice (achieving QTS cross-curricular strand). Exeter: Learning Matters.

Winnicott, D. W. (1964) The child, the family and the outside world. Harmondsworth: Penguin.

Wu, J. J., \& Albanese, D. (2010). Asian creativity, chapter one: Creativity across three Chinese societies. Thinking Skills and Creativity, 5, 150-154. doi:10.1016/j.tsc.2010.10.002

Yin, R. K. (2003). Case study research: Design and methods. California: Sage. 


\section{Appendices}

Observation checklist

\begin{tabular}{|c|c|c|c|}
\hline Domain & Item & Yes & No \\
\hline \multirow{6}{*}{$\begin{array}{l}\text { Activity } \\
\text { Type }\end{array}$} & - $\quad$ role play & & \\
\hline & - $\quad$ explorations & & \\
\hline & - drama & & \\
\hline & - $\quad$ storytelling & & \\
\hline & - $\quad$ discussion & & \\
\hline & - empathy & & \\
\hline \multirow{3}{*}{$\begin{array}{l}\text { Students' } \\
\text { Autonomy }\end{array}$} & - Open ended for students' self-expression & & \\
\hline & - $\quad$ Open ended for students' imagination. & & \\
\hline & - $\quad$ Restrict students' exploration. & & \\
\hline \multirow[t]{3}{*}{$\begin{array}{l}\text { Features of } \\
\text { Scaffolding }\end{array}$} & $\begin{array}{l}\text { - } \begin{array}{l}\text { Very sensitive to scaffolding students' } \\
\text { imagination. }\end{array} \\
\text { ' }\end{array}$ & & \\
\hline & - $\quad$ attempts scaffolding from time to time & & \\
\hline & - $\quad$ never attempts scaffolding & & \\
\hline
\end{tabular}

\section{Interview sheet}

1. What is imaginative teaching?

2. What are imaginative teaching processes in religious education subject?

3. What are the imaginative teaching products?

4. How can teachers help sixth grade students to be imaginative? (e.g., teaching processes)? 